\title{
Torrefaction of Acacia nilotica: oxygen distribution and carbon densification mechanism based on in-depth analyses of solid, liquid and gaseous products
}

\author{
Satyansh Singh, Jyoti Prasad Chakraborty*, Monoj Kumar Mondal \\ Department of Chemical Engineering and Technology \\ Indian Institute of Technology (Banaras Hindu University) Varanasi-221005, India \\ *Corresponding Author: E-mail: jpc.che@iitbhu.ac.in Phone: +919795396580
}

\section{Supplementary material}

\section{Procedure S1}

The mass of gaseous product can be obtained by using the following procedure:

Flow rate of nitrogen gas $=v \mathrm{~mL} / \mathrm{min}$

Volume of nitrogen $\left(V_{1}\right)$ through mass flow controller $=$ Flow rate of nitrogen gas $\times$ time $=v$ $\times \mathrm{t}$

By applying ideal gas equation between outlet of the mass flow controller and outlet of the setup, the volume of nitrogen gas at outlet of the set-up $\left(V_{2}\right)$ may be calculated from Eq (3).

$$
\frac{P_{1} V_{1}}{T_{1}}=\frac{P_{2} V_{2}}{T_{2}}
$$


where $P_{1}, V_{1}$, and $T_{1}$ is the pressure, volume, and temperature, respectively at outlet of mass flow controller, $P_{2}, V_{2}$, and $T_{2}$ is the pressure, volume, and temperature, respectively, at the outlet of the set-up.

The mole of nitrogen at outlet of set-up can be calculated using Eq. (4)

Moles of nitrogen gas $\left(n_{N_{2}}\right)=\frac{P_{2} V_{2}}{Z R T_{2}}$

where $\mathrm{Z}$ is the compressibility factor of nitrogen at outlet condition of set-up (101325 Pa and ambient temperature). The temperature at the outlet may vary according to seasonal condition.

Mass of nitrogen gas $\left(m_{N_{2}}\right)$ at outlet $=n_{N_{2}} \times$ molecular mass of nitrogen

Mass of different component of gases with respect to nitrogen gas can be calculated using Eq. (6).

$\frac{m_{x_{i}}}{m_{N_{2}}}=$ C.F. $\times \frac{\text { average area }}{\text { average } \text { area }_{N_{i}}} \quad$ i varies from 1 to 4

where $\mathrm{x}_{\mathrm{i}}$ is the component of gaseous products such as $\mathrm{H}_{2}, \mathrm{CO}, \mathrm{CH}_{4}$, and $\mathrm{CO}_{2}$; C.F. is the calibration factor for a component with respect to $\mathrm{N}_{2}$, as determined by using a standard calibration mixture procured from Chemtron Science Laboratory, Mumbai, India. 


\section{Procedure S2}

\section{Proximate and ultimate analysis and HHV of raw and torrefied biomass}

The standard protocols ASTM E871, ASTM E1755, and ASTM E872 were followed to calculate moisture content (MC), ash content (AC), and volatile matter (VM), respectively, of raw and torrefied biomass. The fixed carbon content (FC) of the samples was obtained by difference. The CHNS analyzer instrument and software (EURO EA3000, EURO VECTOR, Italy) was used to investigate the elemental composition of raw and torrefied biomass. The elemental oxygen content was obtained by difference, assuming insignificant sulfur content. The HHV of raw and torrefied biomass and liquid condensates were calculated by using a Bomb calorimeter (IKA, C200 model, Germany).

\section{TGA analysis}

The thermal behavior of raw and torrefied biomass was investigated using TGA (Perkin Elmer STA 6000). Nitrogen gas was used as a carrier gas at a flow rate of $20 \mathrm{~mL} / \mathrm{min} .5 \mathrm{mg}$ of each biomass sample was taken into the alumina crucible for the best possible heat transfer during pyrolysis. TGA was performed at a heating rate of $10^{\circ} \mathrm{C} / \mathrm{min}$ in the temperature range of 25 to $800{ }^{\circ} \mathrm{C}$.

\section{FTIR analysis}

The FTIR analyzer (Varian 1000, USA) was used to reveal the structural modification in biomass as a result of torrefaction. Potassium bromide $(\mathrm{KBr})$ was mixed with raw and torrefied biomass to make the pellets. The spectrum was recorded in wavenumbers ranging from 4000 to $400 \mathrm{~cm}^{-1}$.

\section{XRD analysis}


The crystalline behavior of raw and torrefied biomass was studied by X-ray diffractometer (XRD, model mini flux II, Rigaku, Japan) with a scanning rate of $5^{\circ}$ per min with a step size of $0.02^{\circ}$ in the range of 0 to $80^{\circ}(2 \theta)$. Eq. (7) was followed to measure the crystallinity index.

$\operatorname{CrI}(\%)=\left(\frac{I_{002}-I_{a m}}{I_{002}}\right) \times 100$

where, $\mathrm{CrI}$ denotes crystallinity index, $\mathrm{I}_{002}$ denotes intensity of diffraction from 002 plane at $2 \theta=$ 22.2, and $\mathrm{I}_{\mathrm{am}}$ denotes the intensity measured at $2 \theta=18.2^{1,2}$.

\section{Gas Chromatography (GC-TCD)}

The gas sample was analyzed in gas chromatography (GC-TCD Centurion Scientific, model number-5800, New Delhi). Argon was used as the carrier gas. GC-TCD was coupled with Carboseive SII packed bed column having a length of 10 feet and an inner diameter of $2.1 \mathrm{~mm}$. The injector, column, and detector temperature were 80,60 , and $150^{\circ} \mathrm{C}$, respectively.

\section{GC-MS analysis}

The GC-MS (TURBOMASS \GBPIC GCMS.PRO) was used to determine the relative abundance of different chemical compounds. Helium was used as a carrier gas. $1 \mu \mathrm{L}$ of the sample was injected in the capillary column (Elite-5MS) (length $60.0 \mathrm{~m}$, inner diameter $250 \mu \mathrm{m}$, film thickness $250 \mu \mathrm{m}$ ) with a split ratio of $10: 1$, while injector temperature was maintained at $280^{\circ} \mathrm{C}$. The initial oven temperature was $60^{\circ} \mathrm{C}$ for 2 min and then increased up to $140{ }^{\circ} \mathrm{C}$ with a ramping rate of $5{ }^{\circ} \mathrm{C} / \mathrm{min}$ and a holding time of $5 \mathrm{~min}$. The temperature was increased to $300{ }^{\circ} \mathrm{C}$ with a ramping rate of $5{ }^{\circ} \mathrm{C} / \mathrm{min}$ and held constant for $5 \mathrm{~min}$. Stationary phase is $5 \%$ diphenyl $95 \%$ dimethyl polysiloxane. 
Interpretation of the peaks appeared in the GC Chromatogram were done by library search of the mass spectrum of corresponding peaks using the database software of National Institute Standard and Technology- 2008 (NIST-2008). The mass spectrums of the unknown components were compared with the spectrum known components of NIST library and the compounds were identified with name, molecular weight, empirical formula etc.

\section{${ }^{13} \mathrm{C}$ NMR analysis}

${ }^{13} \mathrm{C}$ nuclear magnetic resonance spectrometry was employed to analyze the various type of carbon and their distribution of liquid condensate obtained at different conditions. The liquid condensate was dissolved in deuterated chloroform $\left(\mathrm{CDCl}_{3}\right)$, and NMR spectra were recorded by Bruker $500 \mathrm{MHz}$ spectrometer (Magnetic system 500'54 ascend ULH) operating at $5 \mathrm{~T}$ with a 5 $\mathrm{mm} \mathrm{BBO} \mathrm{BB}-1 \mathrm{H}$ probe at room temperature with a relaxation delay of $2 \mathrm{~s}$. 
Table S1 Type of carbon in different range of chemical shift

\begin{tabular}{cc}
\hline Chemical shift $(\mathrm{ppm})$ & Type of carbon \\
\hline $0-45$ & Alkyl carbon \\
$45-65$ & Methoxyl and N-alkyl carbon \\
$65-90$ & O-alkyl carbon \\
$90-110$ & Di-O-alkyl carbon \\
$110-145$ & Aryl and unsaturated carbon \\
$145-165$ & O-aryl carbon \\
$165-190$ & Carbonyl and amide carbon \\
$190-215$ & Aldehyde and ketone carbon \\
\hline
\end{tabular}


Table S2 GC-MS analysis of liquid products obtained at different torrefaction temperature and 30 min residence time

\begin{tabular}{|c|c|c|c|c|c|}
\hline \multirow[t]{2}{*}{ Compounds } & \multirow{2}{*}{$\begin{array}{l}\text { Molecular } \\
\text { formula }\end{array}$} & \multicolumn{4}{|c|}{$\begin{array}{l}\text { Relative content (peak area }(\%)) \\
\end{array}$} \\
\hline & & TO-225-30 & TO-250-30 & TO-275-30 & TO-300-30 \\
\hline \multicolumn{6}{|l|}{ Ketones } \\
\hline 2-Cyclopenten-1-one & $\mathrm{C}_{5} \mathrm{H}_{6} \mathrm{O}$ & ND & 1.27 & 1.09 & 0.87 \\
\hline 1,2- Cyclopentanedione & $\mathrm{C}_{5} \mathrm{H}_{6} \mathrm{O}_{2}$ & ND & 3.85 & 4.63 & 3.76 \\
\hline 2-ethyl-5-propylcyclopentanone & $\mathrm{C}_{10} \mathrm{H}_{18} \mathrm{O}$ & 2.34 & 1.22 & 4.18 & 4.00 \\
\hline 2-Cyclopentene-1-one,3-ethyle-2-hydroxy- & $\mathrm{C}_{7} \mathrm{H}_{10} \mathrm{O}_{2}$ & 1.82 & 1.56 & 1.33 & 1.47 \\
\hline 2-Propanone, 1-(4-hydroxy-3-methoxyphenyl)- & $\mathrm{C}_{10} \mathrm{H}_{12} \mathrm{O}_{3}$ & ND & 0.72 & 1.09 & 1.36 \\
\hline Ethanone, 1-(3-hydroxy-4-methoxyphenyl)- & $\mathrm{C}_{9} \mathrm{H}_{10} \mathrm{O}_{3}$ & ND & ND & 1.26 & 0.90 \\
\hline 2H-1-benzopyran-2-one, 3,4Dihydro-6-hydroxy & $\mathrm{C}_{9} \mathrm{H}_{8} \mathrm{O}_{3}$ & 1.48 & 0.95 & 1.49 & 1.61 \\
\hline Ethanone, 1-(4-hydroxy-3,5-dimethoxyphenyl) & $\mathrm{C}_{10} \mathrm{H}_{12} \mathrm{O}_{4}$ & 2.27 & 1.19 & 1.39 & 2.06 \\
\hline Total & & 7.91 & 10.76 & 16.46 & 16.03 \\
\hline \multicolumn{6}{|l|}{ Aldehydes } \\
\hline 2-Butenal,2-methyl- & $\mathrm{C}_{5} \mathrm{H}_{8} \mathrm{O}$ & 1.39 & 2.07 & 2.23 & 2.35 \\
\hline Benzaldehyde,4-hydroxy-3,5-dimethoxy- & $\mathrm{C}_{9} \mathrm{H}_{10} \mathrm{O}_{4}$ & 2.81 & 1.17 & 1.39 & 2.63 \\
\hline Total & & 4.20 & 3.24 & 3.62 & 4.98 \\
\hline \multicolumn{6}{|l|}{ Acid } \\
\hline 3,5-dimethoxy-4-hydroxyphenylacetatic acid & $\mathrm{C}_{10} \mathrm{H}_{12} \mathrm{O}_{5}$ & 3.15 & 3.21 & 3.67 & 4.54 \\
\hline Total & & 3.15 & 3.21 & 3.67 & 4.54 \\
\hline \multicolumn{6}{|l|}{ Alcohol } \\
\hline Maltol & $\mathrm{C}_{6} \mathrm{H}_{6} \mathrm{O}_{3}$ & ND & 0.88 & 0.90 & 1.15 \\
\hline 2-Buten-1-ol & $\mathrm{C}_{4} \mathrm{H}_{8} \mathrm{O}$ & 6.69 & 4.95 & 7.01 & 7.15 \\
\hline 3-Octanol,2,6-dimethyl- & $\mathrm{C}_{10} \mathrm{H}_{22} \mathrm{O}$ & ND & 0.82 & 1.03 & 0.94 \\
\hline Total & & 6.69 & 6.65 & 8.94 & 9.24 \\
\hline \multicolumn{6}{|l|}{ Furan derivatives } \\
\hline Furan,2,5-dimethyl- & $\mathrm{C}_{5} \mathrm{H}_{4} \mathrm{O}_{2}$ & 4.94 & 5.00 & 5.17 & 8.63 \\
\hline 2-Furancarboxaldehyde, 5-methyl- & $\mathrm{C}_{6} \mathrm{H}_{6} \mathrm{O}_{2}$ & ND & ND & 1.22 & 1.02 \\
\hline 2-Furancarboxaldehyde, 5-(hydroxymethyl)- & $\mathrm{C}_{6} \mathrm{H}_{6} \mathrm{O}_{3}$ & 1.52 & 1.86 & 1.86 & 1.66 \\
\hline 1,4:3,6-Dianhydro-Alpha-D-Glucopyranose & $\mathrm{C}_{6} \mathrm{H}_{8} \mathrm{O}_{4}$ & 1.40 & 1.19 & 0.93 & 1.27 \\
\hline 1,6-Anhydro-Beta-D-Glucofuranose & $\mathrm{C}_{6} \mathrm{H}_{10} \mathrm{O}_{5}$ & ND & ND & ND & 0.85 \\
\hline Total & & 7.86 & 8.05 & 9.18 & 13.43 \\
\hline
\end{tabular}




\section{Phenol derivatives}

Phenol, 2-methoxy-

Phenol, 2-methoxy-4-methyl-

$\mathrm{C}_{7} \mathrm{H}_{8} \mathrm{O}_{2}$

$\mathrm{C}_{8} \mathrm{H}_{10} \mathrm{O}_{2}$

1.45

$\mathrm{C}_{9} \mathrm{H}_{12} \mathrm{O}_{2} \quad 1.40$

Phenol, 4-ethyl-2-methoxy-

Phenol, 2,6-dimethoxy-

$\mathrm{C}_{8} \mathrm{H}_{10} \mathrm{O}_{3}$

6.27

Vanillin

Phenol, 2,6-Dimethoxy-4-(2-propenyl)-

$\mathrm{C}_{8} \mathrm{H}_{8} \mathrm{O}_{3}$

1.53

$\mathrm{C}_{11} \mathrm{H}_{14} \mathrm{O}_{3}$

1.21

\section{Total}

14.28

3.08

4.35

4.70

Amine

Benzedrex

Methamphetamine, Propionyl

Total

$\mathrm{C}_{10} \mathrm{H}_{21} \mathrm{~N}$

1.18

$\mathrm{C}_{13} \mathrm{H}_{19} \mathrm{ON}$

ND

1.18

\subsection{8}

1.89

1.10

1.78

1.05

\section{Anhydride}

2-Methylbutanoic Anhydride

\section{Total}

Ester

Methyl Propionate

Tert-Butyl Acrylate

I-Propyl 10-Methyl-Dodecanoate

\section{Total}

Other

1,2,4-Trimethoxybenzene

Benzene, 1,2,3-Trimethoxy-5-methyl-

D-Allose

Total

$\mathrm{C}_{10} \mathrm{H}_{18} \mathrm{O}_{3}$

ND

1.27

18.46

$\mathrm{C}_{4} \mathrm{H}_{8} \mathrm{O}_{2} \quad 2.06$

$\mathrm{C}_{7} \mathrm{H}_{12} \mathrm{O}_{2}$

ND

$\mathrm{C}_{16} \mathrm{H}_{32} \mathrm{O}_{2}$

ND

3.54

18.15

2.75

3.32

1.19

1.26

0.85

4.51

4.01

ND

1.07

1.01

1.07

1.01

2.06

2.51

1.77

4.05

ND

ND

0.81

ND

1.81

1.39

6.25

$\mathrm{C}_{9} \mathrm{H}_{12} \mathrm{O}_{3}$

2.52

2.51

3.58

3.72

$\mathrm{C}_{10} \mathrm{H}_{14} \mathrm{O}_{3}$

2.74

4.87

4.81

3.21

$\mathrm{C}_{6} \mathrm{H}_{12} \mathrm{O}_{6}$

4.27

3.80

3.74

7.21

9.53

19.23

14.94

14.14 
Fig. S1 Compositional analysis of raw and torrefied biomass based on the method enumerated by Bledzki et al. ${ }^{3}$

\section{Extraction of Lignin content}

$2 \mathrm{~g}$ of biomass sample $+15 \mathrm{ml} \mathrm{H}_{2} \mathrm{SO}_{4}(72 \%)$ was added, and the mixture was stirred frequently for two and half hours at $25^{\circ} \mathrm{C}$

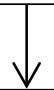

$200 \mathrm{ml}$ of distilled water were added to the mixture and then the mixture was boiled for next two hours and cooled

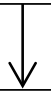

After $24 \mathrm{~h}$, the lignin was transferred to the crucible and washed with hot water repeatedly until becoming acid free

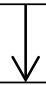

The collected lignin was dried at $105^{\circ} \mathrm{C}$ and cooled down in desiccator and weighed

\section{Extraction of Holocellulose content}

$3 \mathrm{~g}$ of air dried sample was weighed and placed in conical flask

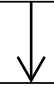

$160 \mathrm{ml}$ of distilled water, $0.5 \mathrm{ml}$ of glacial acetic acid and $1.5 \mathrm{~g}$ of $\mathrm{NaCl}$ were added and flask was placed in water bath and heated up to $75^{\circ} \mathrm{C}$ for an hour

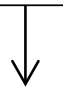

Again, $0.5 \mathrm{ml}$ of glacial acetic acid and $1.5 \mathrm{~g}$ of sodium chloride were added (repeated two times hourly)

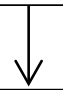

The flask was placed in an ice bath and cooled down below $10{ }^{\circ} \mathrm{C}$

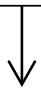

The holocellulose was filtered and washed with acetone, ethanol and water

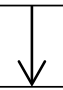

The sample was dried in oven at $105^{\circ} \mathrm{C}$ before weighed 


\section{Extraction of Cellulose content}

$2 \mathrm{~g}$ of holocellulose were placed in a beaker and $10 \mathrm{ml}$ of $\mathrm{NaOH}$ solution $(17.5 \%)$ was added

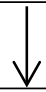

The fibres were stirred up by glass rod so that they could be soaked with sodium hydroxide solution vigorously

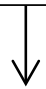

Then $\mathrm{NaCl}$ solution was added to the mixture periodically (once every $5 \mathrm{~min}$ ) for half an hour and the mixture temperature was kept at $20^{\circ} \mathrm{C}$

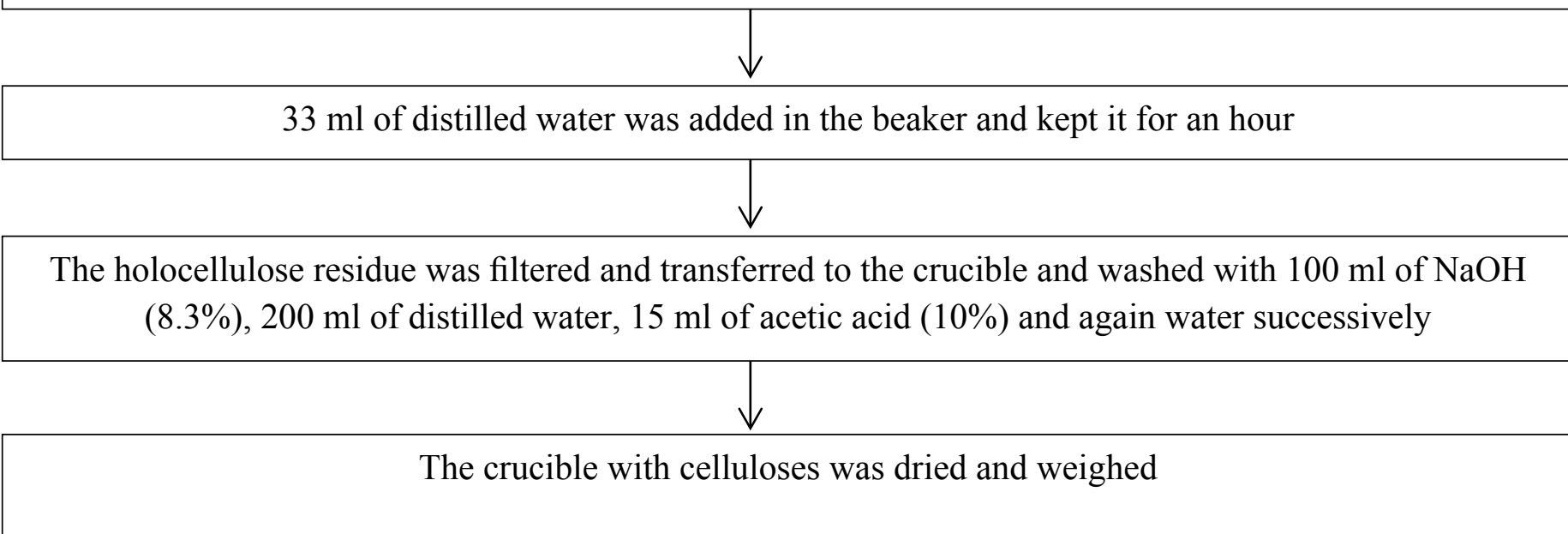

\section{Extraction of Hemicellulose content}

Hemicellulose $=$ Holocellulose - Cellulose 
Fig. S2 Profiles of product yield with variation of temperature

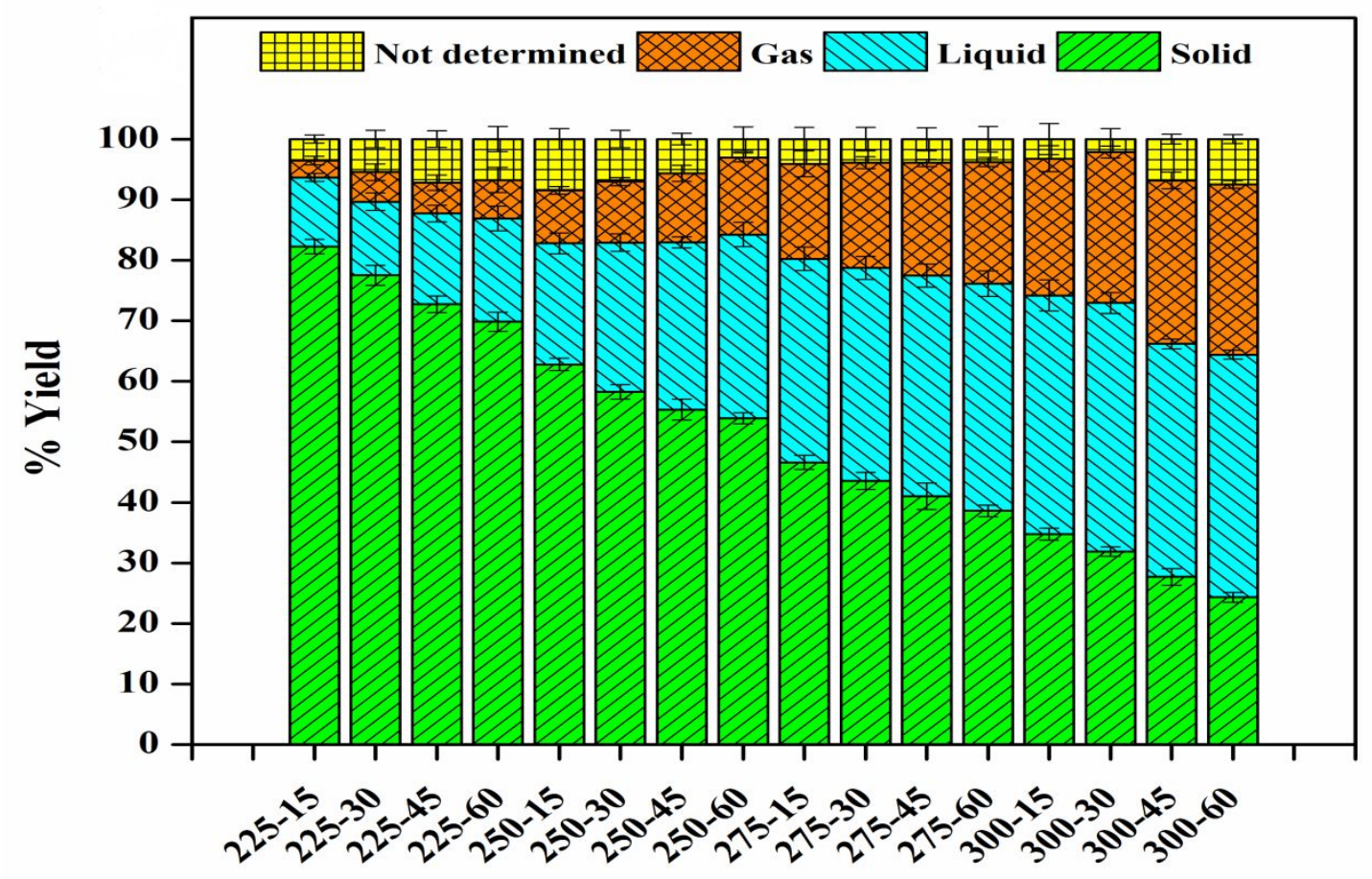

Fig. S3 van Krevelan diagram of raw and torrefied biomass

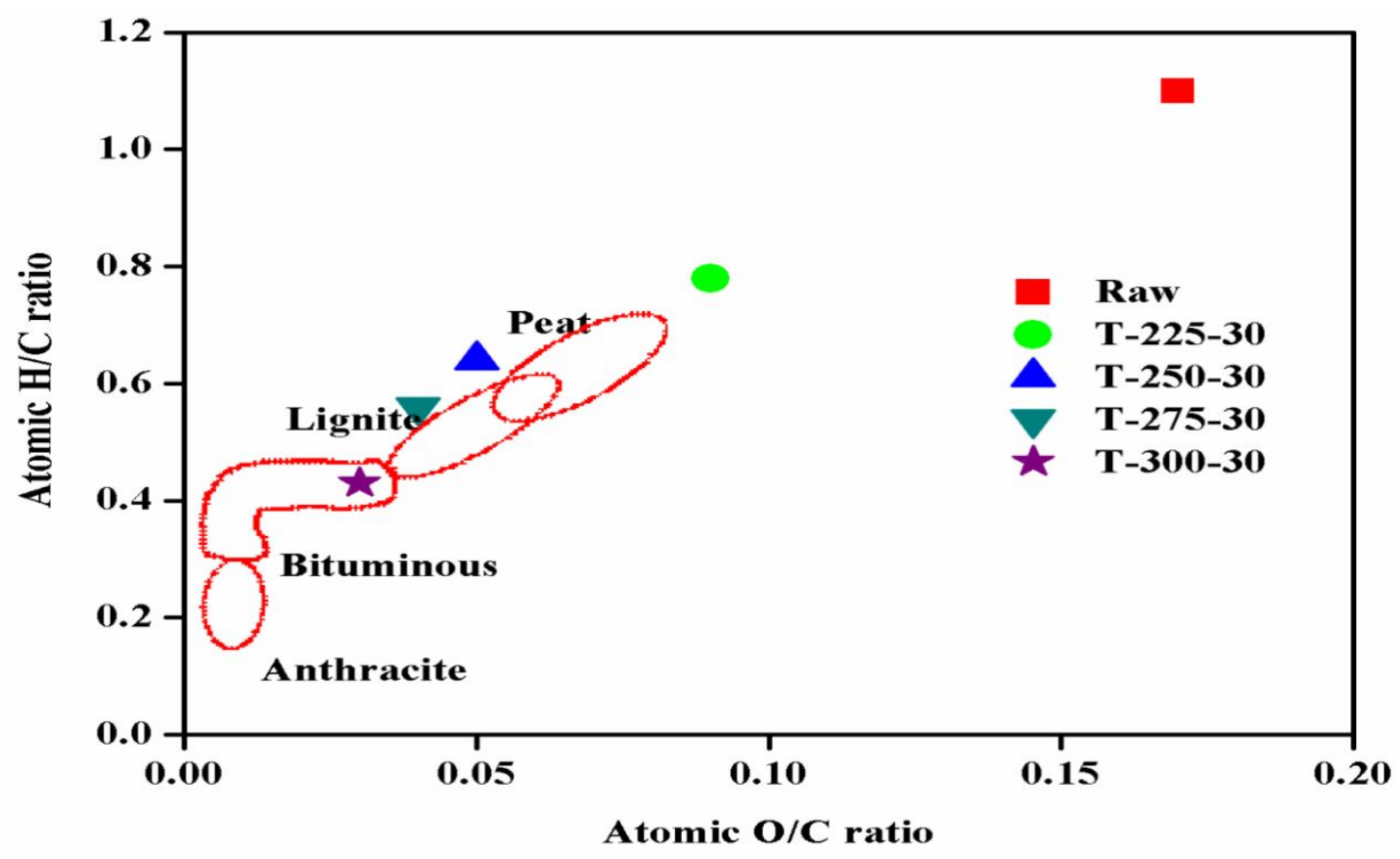


Fig. S4 ${ }^{13} \mathrm{C}$ NMR spectra of liquid condensate obtained at different temperature and $30 \mathrm{~min}$ retention time

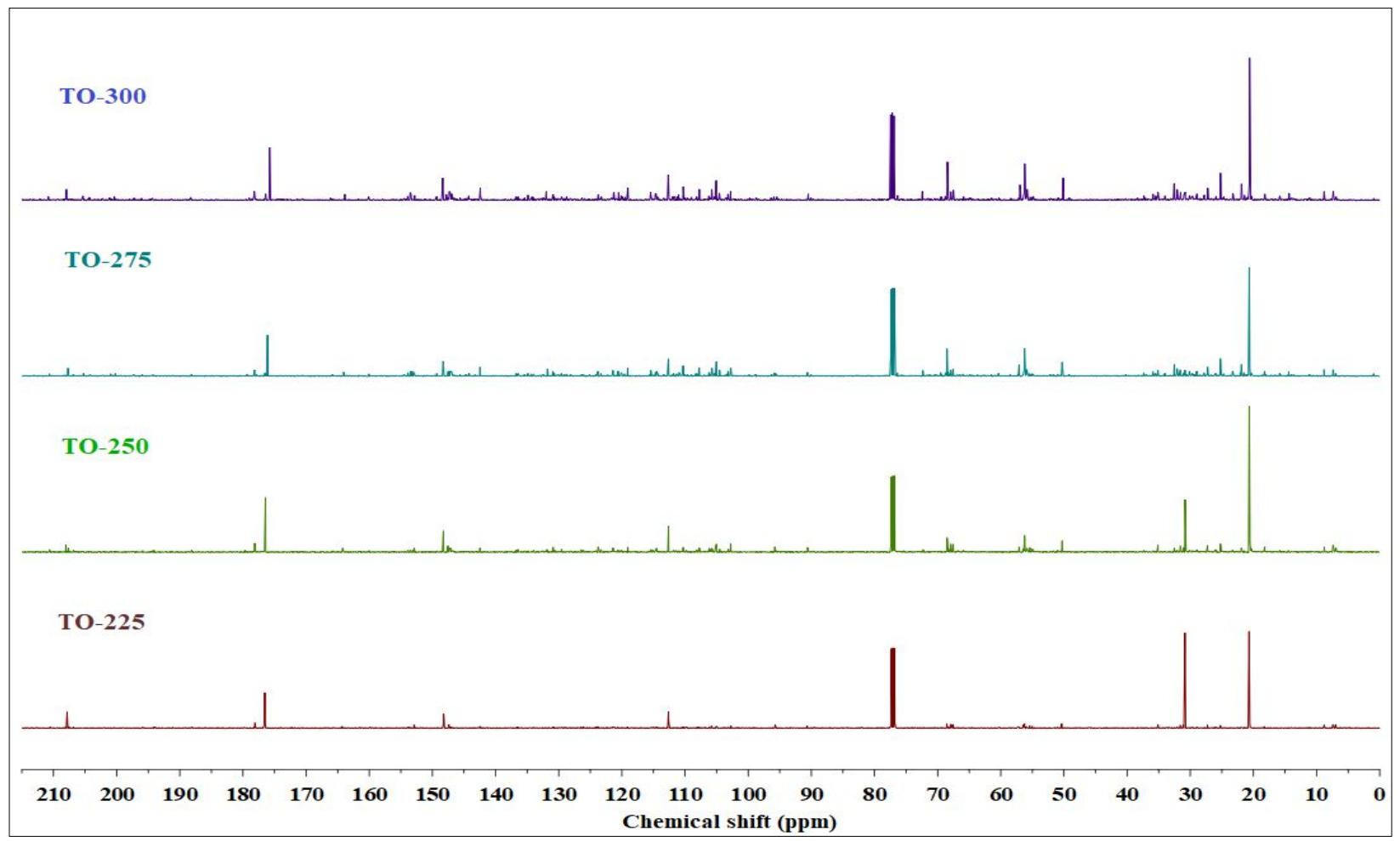


Fig. S5 GC-MS spectra of liquid condensate obtained at different temperature and $30 \mathrm{~min}$ residence time

Fig. S5 (a)

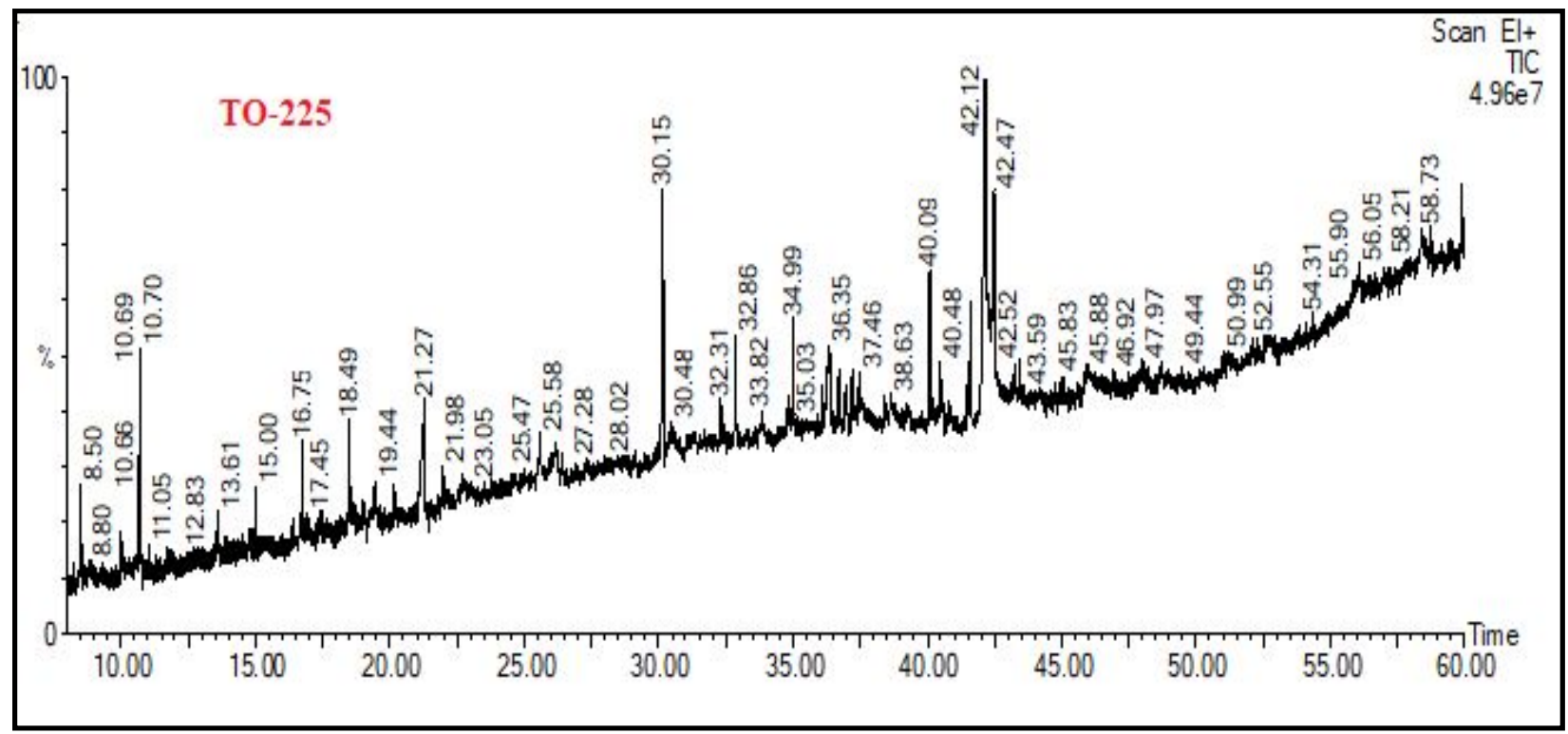

Fig. S5 (b)

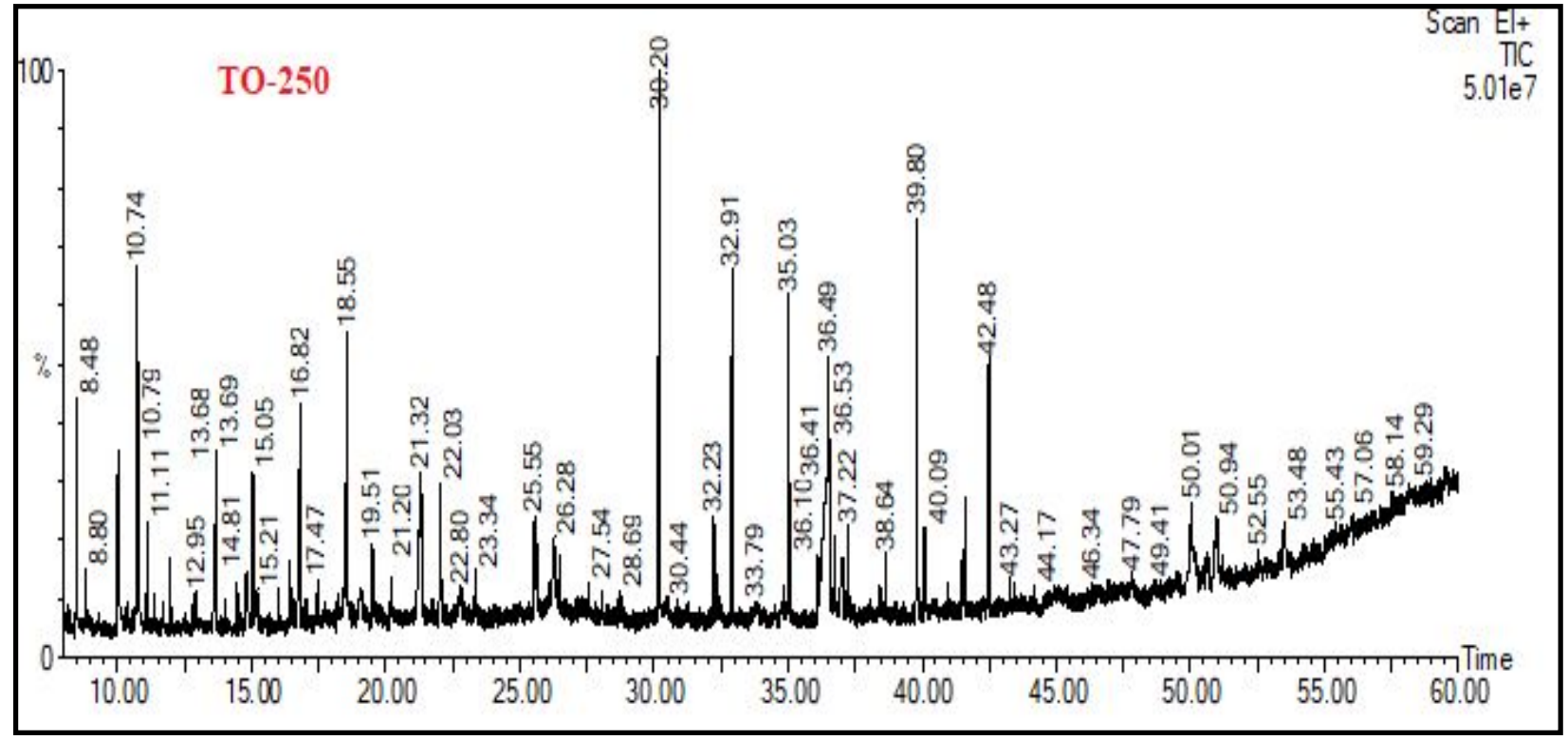


Fig. S5 (c)

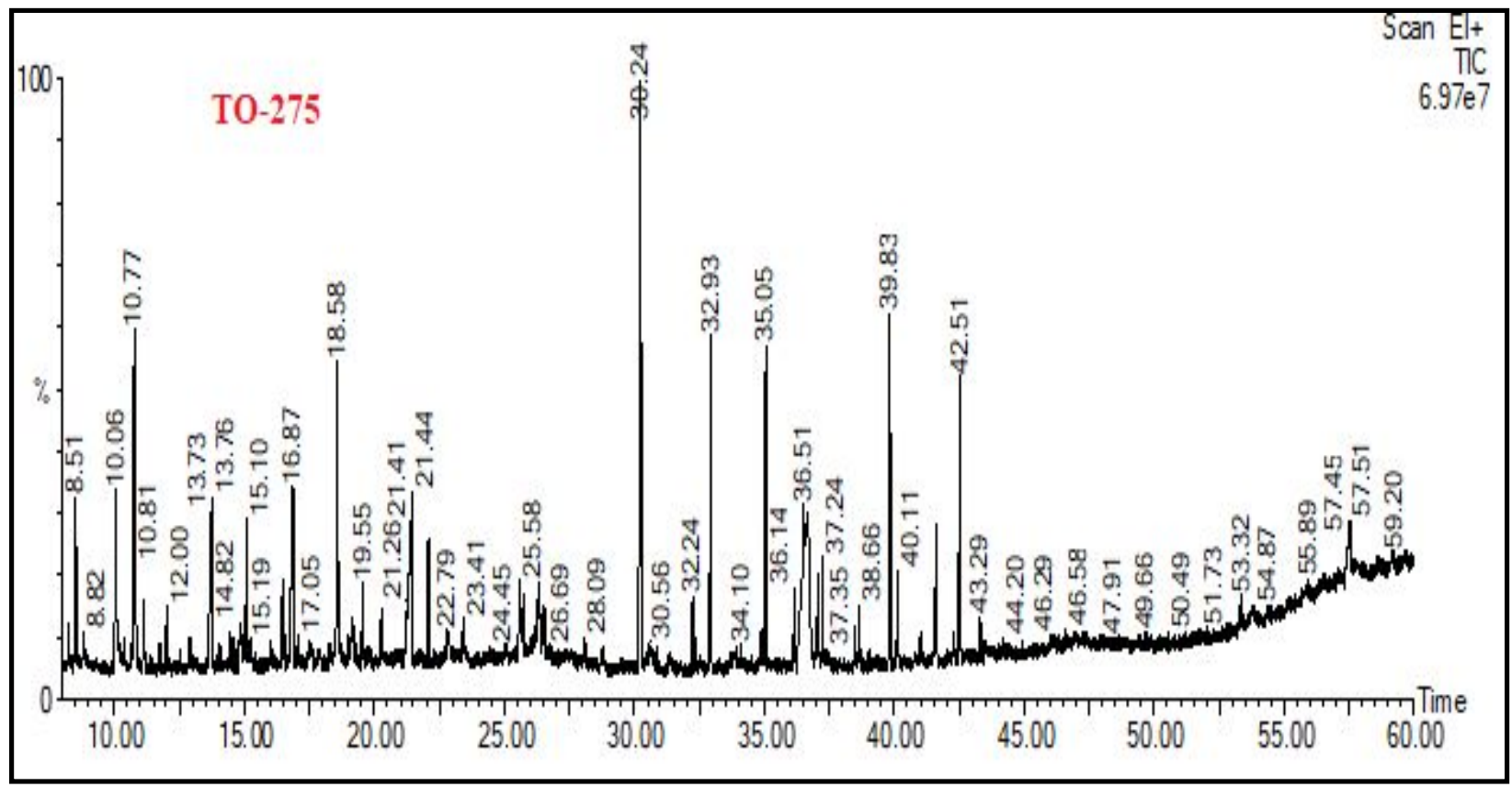

Fig. S5 (d)

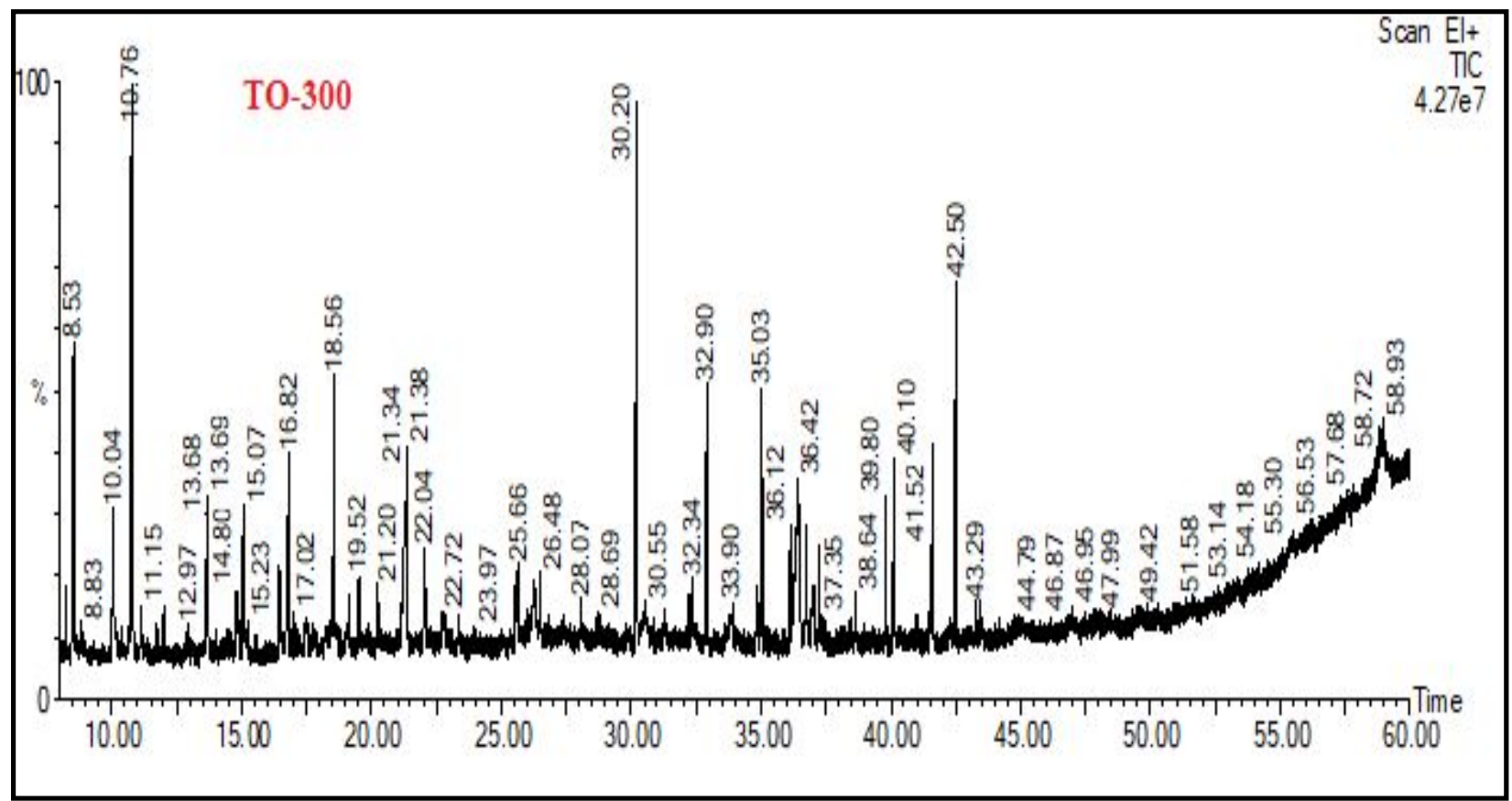




\section{References}

1. $\quad$ S. Kim and M. T. Holtzapple, Bioresour. Technol., 2006, 97, 583-591.

2. Q. Dong, S. Zhang, K. Ding, S. Zhu, H. Zhang and X. Liu, Biomass and Bioenergy, 2018, 119, 229-236.

3. A. K. Bledzki, A. A. Mamun and J. Volk, Compos. Part A: Appl. Sci. Manufact., 2010, $41,480-488$. 